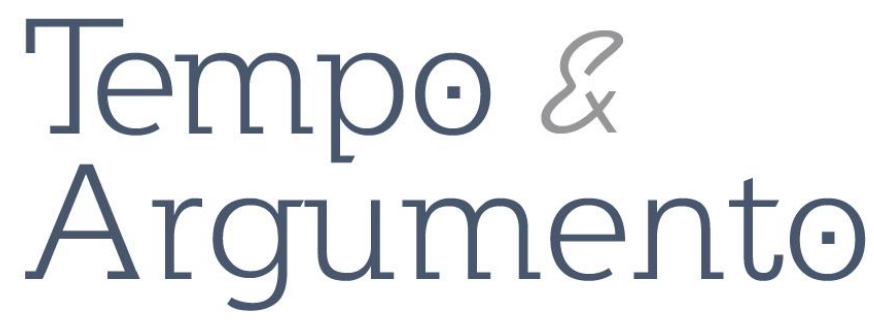

\title{
Os "cravos" da memória: democracia e passado autoritário em Portugal
}

\section{Resenha da obra:}

RAIMUNDO, Filipa. Ditadura e Democracia: legados da memória. Lisboa: Fundação Francisco Manuel dos Santos, 2018.

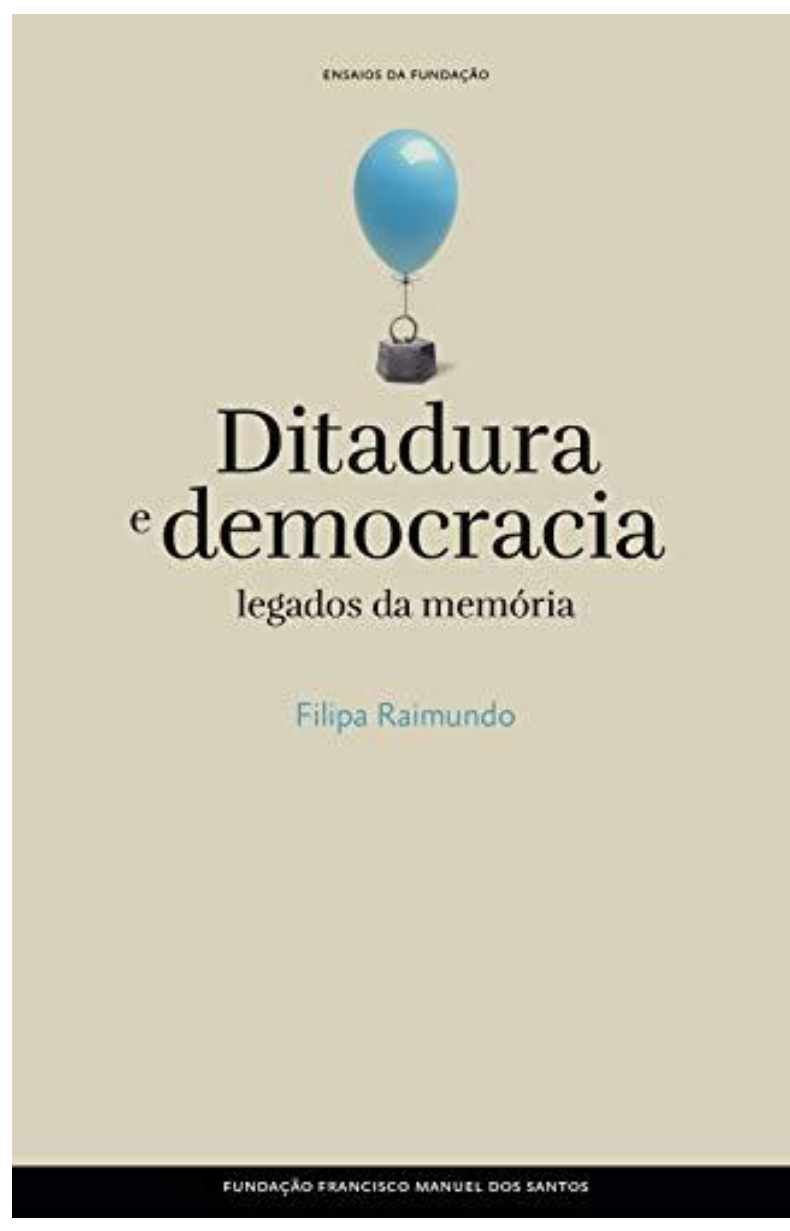

Autor da resenha

\section{Paulo Renato da Silva}

Doutor em História pela Universidade Estadual de Campinas (UNICAMP). Professor da Universidade Federal da Integração Latino-Americana (UNILA).

Foz do Iguaçu, PR - BRASIL

paulo.silva@unila.edu.br orcid.org/0000-0002-6603-0419

\section{Para citar esta resenha:}

RAIMUNDO, Filipa. Ditadura e Democracia: legados da memória. Lisboa: Fundação Francisco Manuel dos Santos, 2018. Resenha de: SILVA, Paulo Renato da. Os "cravos" da memória: democracia e passado autoritário em Portugal. Revista Tempo e Argumento, Florianópolis, v. 11, n. 28, p. 546 - 552. set/dez. 2019. 
Ditadura e Democracia: legados da memória, da socióloga Filipa Raimundo, foi publicado em 2018 pela Fundação Francisco Manuel dos Santos. O livro é o $87^{\circ}$ da coleção "Ensaios da Fundação", uma das mais importantes coleções portuguesas tendo em vista a publicação de títulos que superem o meio acadêmico.

Escrito em linguagem acessível - mas não simplista -, e bem estruturado, o livro é composto por uma introdução, quatro capítulos e uma conclusão. Na introdução, De que é que trata este livro?, a autora evidencia o propósito do livro, a análise “(...) da relação da democracia portuguesa com o seu passado autoritário e dos elementos que têm contribuído para a construção da memória deste período (...)” (p. 9). No caso de Portugal, o passado autoritário se refere ao Estado Novo (1933-1974), período marcado pelo governo de António de Oliveira Salazar (1889-1970), Presidente do Conselho de Ministros entre 1932 e 1968, quando sofreu um acidente e foi afastado de suas funções. A Revolução dos Cravos, de 25 de abril de 1974, representou o fim da ditadura do Estado Novo ${ }^{1}$. Para leitores que não sejam de Portugal, é importante acrescentar que o primeiro governo constitucional eleito depois da ditadura se estabeleceu apenas em julho de 1976, informação que ajudará a compreender alguns elementos tratados no livro e críticas feitas à condução da Revolução dos Cravos por diferentes grupos políticos portugueses.

O capítulo 1, Democracia e passado autoritário, destaca como as democracias de cada país se relacionam de modo diferente com os seus respectivos passados autoritários. “A decisão de punir ou não os responsáveis pelo regime deposto é, em larga medida, um produto das condições políticas existentes durante a mudança de regime. (...). Mais tarde, só conjunturas críticas permitem mudar a relação entre um povo e o seu passado autoritário" (p. 17). No capítulo 2, Ajustar contas com o passado, Raimundo passa a focar no caso português; analisa como alguns nomes ligados ao Estado Novo sofreram sanções institucionais e políticas depois da queda da ditadura e como outros foram processados criminalmente pelos atos cometidos. O capítulo 3, Romper com o passado, mas sem o apagar, analisa as novas narrativas sobre o passado promovidas a partir da Revolução dos Cravos, “(...) acções no plano simbólico e museológico [que] permitiram 
que a democracia se legitimasse tanto por oposição como por rejeição ao regime anterior, mesmo que ela nem sempre tenha sido tão profunda quanto a narrativa revolucionária faria supor" (p. 55). No capítulo 4, O antifascismo como imagem de marca, a autora investiga o tema das reparações econômicas e simbólicas aos perseguidos pela ditadura até os dias atuais. No início, as associações de perseguidos tinham o principal objetivo de libertar os presos políticos e “(...) sua existência foi relativamente efémera, tendo em conta a relativa rapidez com que os presos políticos foram libertados" (p. 77). Atualmente, poucas associações reuniriam ex-membros da oposição e da resistência e as atuais propostas de reconhecimento estariam muito concentradas nas mãos dos partidos políticos. Enquanto as associações primariam pelo reconhecimento simbólico, dos partidos políticos viriam as principais propostas de compensação financeira aos perseguidos. “(...) os beneficiários desses mecanismos parecem ser, em grande medida, os militares e simpatizantes dos partidos que lideram as propostas legislativas" (p. 78). De acordo com Raimundo, a reunião das iniciativas de sucessivos governos e dos principais partidos, sobretudo de esquerda, “(...) mais do que dar resposta a (...) certos sectores da sociedade, poderá ser encarada (...) como uma forma de cultivar uma imagem de marca através da qual podem reforçar as suas credenciais democráticas e chamar a si a herança da luta pela democracia e contra o autoritarismo" (p. 78). Na Conclusão, a autora faz um balanço do tratado em todo o livro e aponta aquilo que ficou de fora².

Os méritos do livro começam pela própria temática, pois a memória de um passado autoritário é sempre um tema complexo e controverso. Ao abordar o tema, Raimundo sistematiza e analisa as principais ações quanto a esse passado ${ }^{3}$, destacando as contribuições, limites e contradições das medidas adotadas por governos, partidos e

\footnotetext{
2 "Este livro não teve a pretensão de apresentar uma análise exaustiva das ferramentas e mecanismos usados para lidar com o passado em Portugal. (...). Ficaram de fora desta análise muitos outros aspectos, tais como: o exílio forçado da cúpula do regime, a punição dos funcionários da Legião Portuguesa, o Tribunal Cívico Humberto Delgado, a mudança na toponímia, a proibição de constituição de partidos fascistas, a amnistia aos desertores e refractários, entre outros temas (...)" (p. 98).

3 No que se refere à sistematização, são dignas de nota as tabelas 1 "Funções abrangidas pela restrição de direitos políticos em 1975-76" (p. 31) e 2 "Temas, conteúdos e principais conclusões dos 25 relatórios publicados pelo Livro Negro" (p. 65). O Livro Negro foi uma proposta iniciada em 1977 pelo primeiro governo constitucional depois da queda da ditadura e teve o objetivo de reunir documentos sobre 0 autoritarismo e a repressão durante o Estado Novo.
} 
associações de perseguidos pela ditadura. Além disso, a autora evidencia as relações entre esse passado e a política portuguesa contemporânea, indicando como os usos dessa memória variam entre governos e partidos de diferentes vertentes políticas. Já comentamos que, segundo o livro, os usos desse passado estariam relacionados à construção de "credenciais democráticas" para os partidos e governos e a maioria das propostas de reconhecimento dos perseguidos partiria de governos e partidos de esquerda. Entretanto, ainda que não haja reivindicação do passado autoritário pelos atuais partidos portugueses, a autora demonstra que existem divergências sobre o reconhecimento aos perseguidos e a condução do processo revolucionário, o que aponta para diferentes concepções de democracia em Portugal após a Revolução dos Cravos. Para mencionar apenas um exemplo tratado no livro, além de indicar divergências existentes entre os próprios partidos de esquerda, Ditadura e Democracia mostra como o CDS, partido conservador português, procurou estender uma lei que beneficiava os perseguidos pela ditadura aos que sofreram sanções pelo processo revolucionário iniciado em abril de 1974, o qual teria cometido abusos semelhantes aos da ditadura:

Como mostram os registros da Assembleia da República, duas semanas depois da aprovação da Lei 20/97, aquele partido [CDS] apresentou uma proposta de alteração da lei que se baseava no facto de muitos portugueses terem sido "perseguidos e vítimas de repressão em virtude das suas convicções democráticas e anticomunistas [grifo meu]. Foram deste modo prejudicados no exercício das suas profissões, afastados ou saneados dos cargos e funções que desempenhavam, impedidos de ensinar, obrigados a recorrer à clandestinidade ou ao exílio, tendo em alguns casos sido presos por longos períodos. (p. 91)

Se na Assembleia existem tensões sobre o tema, na sociedade portuguesa não poderia ser diferente. Raimundo destaca várias reivindicações de António de Oliveira Salazar em Santa Comba Dão, terra natal do ditador, e na imprensa, como o caso do documentário da RTP - uma das principais redes de televisão de Portugal - que apresentou Salazar como o expoente do século XX português (p. 10-14). “Tendo já superado a longevidade do regime autoritário, a democracia portuguesa dificilmente poderá continuar a ser apelidada de 'jovem'. Ainda assim, estes temas surgem no debate com relativa frequência (...)" (p. 14). Ao apontar para as divergências existentes na 
Assembleia e na sociedade portuguesa - ainda que pontuais, esporádicas e minoritárias -, o livro nos leva a considerar que existem elementos que poderiam mudar a relação dos portugueses com seu passado autoritário diante de eventuais "conjunturas críticas", conforme a autora defende no início de Ditadura e Democracia sem mencionar especificamente o caso português.

Ainda sobre a sistematização das ações e medidas tomadas em relação ao passado autoritário português, o livro se destaca pela comparação com o ocorrido em outros países europeus, africanos e latino-americanos, destacando convergências e divergências em relação a Portugal. A autora defende que “(...) o conhecimento sobre a forma como se ajustou contas com o passado noutros países poderá contribuir para mitigar a avaliação negativa que os portugueses fazem do seu próprio processo de ajuste de contas (... )" (p. 53). Raimundo apresenta dados de uma pesquisa que coordenou, na qual 95\% de 131 perseguidos pela ditadura responderam que não teria ocorrido justiça no caso português (p. 51). A autora cita que nos casos de Espanha e Brasil, por exemplo, a opção punitiva não esteve nem sequer à disposição da elite política (p. 53). Além desse esforço de História Comparada, é necessário valorizar, ainda, o diálogo multi e interdisciplinar apresentado pelo livro entre áreas como História, Direito, Ciência Política e Sociologia.

Quanto às polêmicas suscitadas pelo livro, uma delas se refere ao termo "ajuste de contas" para se referir às sanções e processos sofridos por nomes ligados ao Estado Novo depois da Revolução dos Cravos. A polêmica, por exemplo, apareceu em 21 de setembro de 2018 no lançamento do livro no Museu do Aljube - Resistência e Liberdade, uma das principais referências quanto à memória do Estado Novo português. O lançamento no Museu do Aljube contou com comentários de Fernando Rosas e Riccardo Marchi. Rosas foi enfático na crítica ao termo "ajuste de contas": "Ajuste de contas ou responsabilização cívica e criminal de responsáveis da ditadura e dos seus crimes? Ajuste de contas tem um subtexto. É o subtexto da vingança. Não se trata bem de um ajuste de contas. Trata-se de justiça." (2018, 17m30s).

Para leitores da maioria dos países latino-americanos e em particular do Brasil, como é o caso do que aqui escreve, o livro pode soar deveras crítico quanto à forma como a Revolução dos Cravos lidou e como os governos constitucionais têm lidado com a 
memória do passado autoritário português. Deveras crítico, pois muitos de nós ainda esperamos ansiosamente por um "ajuste de contas", ainda que limitado e com imperfeições. Assim, para muitos de nós latino-americanos, ler o livro é experimentar um choque entre a nossa temporalidade e a portuguesa no que se refere à relação com o passado autoritário. Só é possível criticar o "ajuste" com o passado quando o processo foi feito ou pelo menos tentaram fazê-lo.

A crítica feita por Ditadura e Democracia é necessária e muito bem-vinda. Serve de experiência e referência àqueles que ainda esperam por um "ajuste" com o passado. Entretanto, faltou ampliar a contextualização das limitações e contradições apresentadas no caso português. Ressaltamos: os excessos cometidos no pós-25 de Abril de 1974 devem ser lembrados e criticados para (des)construir e historicizar os discursos políticos em Portugal desde então. Devem ser lembrados e criticados, pois, em alguns casos, foram muito graves e resultaram em “(...) diversas prisões arbitrárias, uso de tortura e violenta agressão física" (p. 99-100), conforme apontou comissão constituída para averiguar os excessos. Contudo, esses excessos também estão profundamente relacionados a um estrangulamento do espaço público promovido por décadas pelo Estado Novo. O (re)estabelecimento de princípios legais e constitucionais depois de períodos autoritários não é um processo simples. Por sua vez, que os excessos de Abril sejam "esquecidos" ou silenciados por forças políticas que outrora os promoveram ou defenderam (p. 99-101) também deve ser analisado como um sinal de revisão do passado revolucionário por essas forças e de seu alinhamento - ou submissão - a valores presentes na sociedade portuguesa contemporânea ou em setores expressivos dela. Para além dos interesses imediatos, presentes nos usos que os partidos e governos fazem do passado autoritário, caberia apontar como a experiência democrática transformou as forças políticas portuguesas e provocou mudanças na forma de lidar com a memória da ditadura e da Revolução dos Cravos. Em outras palavras, o "esquecimento" ou o silenciamento dos excessos cometidos por Abril talvez indiquem um aprendizado maior com a democracia do que reivindicações de Salazar em sua terra natal ou em programas de televisão de grande alcance. Enfim, faltou ao livro um equilíbrio entre a crítica à 
memória de Abril e os legados que a Revolução dos Cravos deixou para a democracia portuguesa, o que implica conceber a democracia para além do seu aspecto institucional.

Em tempos nos quais o passado autoritário brasileiro é minimizado ou mesmo negado por expoentes e setores de nossa política e sociedade - o que se verifica com variações em outros países latino-americanos -, a leitura de Ditadura e Democracia nos conecta com experiências históricas vividas pelos portugueses desde a queda da ditadura. Ajuda-nos a pensar nas particularidades de cada processo, mas também nos problemas e dilemas em comum deixados por governos autoritários e ditatoriais. Quanto às críticas que Filipa Raimundo faz aos usos da memória do passado autoritário português e da Revolução dos Cravos, estas nos servem, sobretudo, para que a sociedade civil seja a grande promotora de nosso "ajuste" e, assim, não fiquemos à mercê das instabilidades que marcam a política partidária e institucional. 